\title{
COMMUNICATION AND DECISION MAKING IN NEONATAL INTENSIVE CARE: WHY NARRATIVE MEDICINE MATTERS
}

\author{
Carmen Carvalho',2, Ana Vale ${ }^{3}$ and Susana Magalhães ${ }^{4,5}$ \\ 1Neonatal Intensive Care Unit - Centro Materno Infantil do Norte, Porto- Portugal. carmencarvalho.bioetica@gmail.com \\ ${ }^{2}$ Bioethics PhD Student- Instituto Bioética, Universidade Católica Portuguesa, Porto- Portugal. \\ ${ }^{3}$ Centro de Estudos Interdisciplinares em Educação e Desenvolvimento (CeiED), Universidade Lusófona Porto, Portugal. \\ ${ }^{4}$ Instituto de Investigação e Inovação em Saúde, Universidade do Porto, Portugal. \\ ${ }^{5}$ Universidade Fernando Pessoa, Porto- Portugal.
}

\begin{abstract}
Objective: This paper aims to analyse parents' and health professionals' discourse, regarding four main areas: (1) the experience of care; (2) communication among all stakeholders; (3) ethical issues; (4) and ethical decision-making. Methodology: The authors collected 62 narratives from health professionals and parents whose newborns have been hospitalized for at least 15 days in the neonatal intensive care unit (NICU). We carried out a qualitative content analysis with the support of NVivo software version 12 Pro. Results: The feelings/emotions are present in a high percentage of narratives (mostly negative ones). Parents' learning emphasizes coping strategies. Most narratives focus on communicational aspects. Decision-making is referred to in almost half of the narratives. The ethical issues and questions mentioned are mainly related to decision-making. Conclusion: The present study emphasizes narrative relevance in the alignment of parents' and health professionals' perspectives to promote therapeutic relationships.
\end{abstract}

Keywords: Communication, Decision-Making, Neonatal Intensive Care, Narrative Medicine.

\section{INTRODUCTION}

Technological and therapeutic advances in neonatal intensive care have led to a decrease in neonatal morbidity and mortality in recent decades. All this progress requires adaptation, specific training, technical skills, permanent knowledge updates, protocol adjustments, clinical guidelines and standards of care based on international meta-analyses, and evidence-based medicine. Along with technical and scientific knowledge, it is highly important to promote holistic and comprehensive care to the newborn and family (Purdy \& Wadhwani, 2006). The hospitalization of a newborn in a neonatal intensive care unit (NICU) constitutes a disruptive life event with great impact on family health (Lefkowitz et al., 2010). During this period, parents need to assume new and unknown roles under adverse conditions, such as physical separation from their baby and constraints in contact opportunities, either due to the baby's clinical severity or to maternal illness. Moreover, they fear for the present and future life of their child, while also experiencing feelings of guilt, hope, love, and happiness (Arzani et al., 2015).

Communication is therefore essential to build a relationship based on trust between parents and health professionals (Wigert et al., 2014). This is particularly relevant in the case of distressing news, since coping strategies can only be promoted if skilful communication 
takes place (Clarke-Pounder et al., 2015). The paradigm of new medicine, i.e. evidencebased medicine, is defined as the conscientious and judicious use of current best evidence in clinical investigation, entailing the use of systematic reviews of the best available medical literature under the scrutiny of scientific peer review, randomized controlled tests, and risk/benefit analysis. Such a model can hardly integrate the intersubjective dimension of therapeutic care, leaving both patients and health professionals deprived of their personal needs. This is because, as Cassel (2011) reminds us:

Each of us gets to our illness our own way, it becomes part of our story, and we individualize it by its place in the narrative of our lives. To know that illness we must know something of the person. To know the person, we must know something of the narrative. (p. 156)

The American Academy of Paediatrics (AAP) recommends three key factors of good communication: (1) the quality and quantity of the information provided; (2) the interpersonal dimension (active listening and real interest in parent's feelings and concerns); and (3) the bond between doctors and parents/children (Levetown, 2008). In the neonatal area, communication is not linear between doctors and patients. Neonatologists care for the baby and a significant part of the communicative and relational work is aimed at the parents. The relationship between doctors, newborns, and parents is known as the "neonatal triangle" (Zonza, 2012).

Respect for autonomy as a bioethical principle has provided the foundation for a different relationship between physicians and patients, moving from a paternalistic approach that denied patients the opportunity to take part in healthcare decisions to a dialogical one that allows for shared decision making. This approach aligns with the concept of ethical deliberation by Gracia (2003), "A procedure that aims to reach wise and prudent decisions, obliging us to take others into account, respecting their different beliefs and values, and prompting them to give reasons for their own points of view" (p. 227). Decision-making in neonatology should follow the same general principles applied to patients who cannot participate in decision making, but who should always be considered as part of the decisions taken, since their best interest is the main aim.

Nowadays, neonatologists, nurses and parents rely on moral cumulative past experiences. Decision-making is more transparent and shared among clinicians and parents, despite its potential difficulties, especially when cultural beliefs collide (Hawley \& Morris, 2017). 
Bioethical principles help to maintain moral insight and balance in more difficult decisions (Beals, 2016). Professional guidance for health care staff states that decisions about care and treatment must always be made in the child's best interest and healthcare staff should work in partnership with parents to explore what treatment options might be the best in the child clinical situation (Weiss et al., 2016). A shared-decision making process, when well conducted, allows a balanced involvement of all parties, supporting both the family and the professionals. Finding the right balance between parental autonomy and physician's responsibility in shared-decision making requires insight, empathy, and enormous analytical and communication skills (Lantos, 2018).

Narrative Medicine is of great significance in the health care area. It has opened up a space for critical reflection on terms and concepts, procedures and routines, teamwork, and the relationship among all the stakeholders: physicians, patients, family, and caregivers (Tekiner, 2017). According to Charon (2001), Narrative Medicine "[is] medicine practiced with the narrative competency to recognize, interpret, and be moved to action by the predicament of others" (p. 83). Hurwitz and Spinozzi (2011) point out that Narrative Medicine is mainly an approach that takes into account to the crucial difference between patienthood and personhood, between biology and biography, by underlining the importance of language and representation in healthcare. They wrote:

Narrative Medicine is a practice and an intellectual stance which enables physicians to look beyond the biological mechanisms at the center of conventional approaches to medical practice, towards domains of thought and ways of telling that focus on language and representation, on the emotions and relationships which illuminate health care practice. (Hurwitz \& Spinozzi, 2011, p. 73)

The focus on language and representation by Hurwitz and Spinozzi (2011) reminds us that Narrative Medicine is intimately tied to the so-called linguistic turn in the early $20^{\text {th }}$ century, which consists of identifying language as instrumental to the perception of behavior or events. The visibility of the shaping role of language at doctor-patient encounters fundaments the refusal of the reductionism underpinning current standard medical practice, which is too much focused on auxiliary diagnostic examinations, especially imaging techniques. By developing narrative competences among all health professionals, Narrative Medicine is more ambitious than Patient-Centered Care because its main focus is not to collect more data about the patient, but to set up relationships that allow for the integration of personal data in patients' care, as well as in team work and in individual practice. 
It is not only about gathering more data, it is about questioning the nature of knowledge and how knowledge gains legitimacy (Murphy et al., 2017). Intersubjectivity is at the core of Narrative Medicine and this relational approach has an impact on the quality of communication and of care. Listening is crucial to setting up relation-based medicine, but it will always fall short of its target if it is merely patient-centered, i.e., if it only entails attention and details monitoring. In order to be actually Narrative Medicine-oriented listening, it should imply a co-creation of knowledge, which means that attention should be paid not only to the details shared by patients, but to the interpretation of patients themselves, as well as to how the interaction between patient-physician/other health professionals can shape the proper act of communication.

A narrative approach could help NICU staff to better understand the suffering and feelings experienced by parents, most often conveyed by images and metaphors. Metaphors are a linguistic resource commonly used by narrators and, to that extent, a resource for (qualitative) researchers to interpret the meanings attributed to lived experiences.

According to Lakoff and Johnson (2003), metaphor as linguistic expression "is pervasive in everyday life, not just in language but in thought and action" (p. 4). It reveals how we frame reality, how parents and health professionals see and experience neonatal care from different points of view. The use of metaphor as a linguistic tool may bring the professional and his technical language closer to the patient, using simple and everyday terms, helping to establish more effective and person-centered care relationships.

Through this study, the researchers aimed to answer the question: what do parents' and healthcare professionals' narratives tell about communication and decision making in the NICU? There was a special focus on ethical issues and intervenients' perceptions, feelings and emotions.

This purpose is supported on the assumption that the analysis of such discourse, with special attention to the use of metaphors and images, is an important tool to identify barriers to a trustful and empowering relationship between health professionals and parents at the NICU. 


\section{METHODOLOGY}

We chose to use narrative research, more precisely the categorical approach (Squire et al., 2014), as it is often used when a researcher is concerned with an experience that has been shared by a group of people (Lieblich et. al., 1998). To achieve the purpose of this study, we collected narratives from healthcare professionals (doctors and nurses) working in the Neonatology Department of Centro Materno-Infantil do Norte (CMIN), and from parents who had their newborns hospitalized for at least 15 days in the neonatal intensive care unit (NICU, CMIN) provided that the discharge had occurred more than 2 months before the start of the study.

After obtaining approval from the Hospital Ethics Committee, the Principal Investigator (PI) of the study, a graduate neonatologist, invited the participants to participate with their own written narratives. The PI performed the invitation in two different ways:

1. The PI contacted health professionals (doctors and nurses) by email. This email included a clear explanation of the project and invited them to write their own narratives, focusing on communication, decisional issues, and their personal experience.

2. The PI informed parents about the project in a meeting that took place on the day of a medical appointment and invited them to participate by writing about their experience, in an open and unstructured way. It is important to highlight that the PI was not the assistant physician of the babies at this stage.

We asked all of the participants to write down narratives freely or with a minimum of guidelines in order to minimize the influence of the researcher and to get the personal sense of the reported experience. We used the following exclusion criteria for participants:

- newborn hospitalized for less than 15 days;

- newborn discharged less than two months before the start of the study;

- clinical cases of neonatal deaths followed by pathological grief;

- neonatal deaths having occurred less than six months before the start of the study; and

- social issues, illiteracy or poor capacity for expressing feelings.

A total of 63 health professionals and parents agreed to participate: 22 doctors and 16 nurses from NICU staff and 24 parents (seven with a medical degree and two nurses). The health professionals were mostly women, working in a NICU for longer than 10 years. Within 
the parent's group, the majority had more than 12 years of upper secondary education and the mothers were the main participants. Among the mothers, their main obstetric characteristics were preeclampsia, HELLP syndrome, fetal malformation, and fetal hydrops. As far as the newborns were concerned, the main diagnoses included extreme prematurity (<28 weeks gestation), infectious disease (pneumonia, meningoencephalitis, necrotizing enterocolitis), perinatal asphyxia, metabolic disorders, severe air leak, neurological disorder, twin anemia-polycythemia sequence, and congenital malformation (facial cleft, diaphragmatic hernia, polymicrogyria, Noonan syndrome RAF 1 mutation)

We selected the narratives based on relevance or pertinence of neonatal clinical history and of the underlying experiences, communication, and decision-making processes. After we collected the narratives, we carried out a qualitative content analysis, a type of categorical analysis characterized by analysing each singular narrative first and, after a series of analyses, proceeding with the analysis of the whole corpus, in which each narrative is considered as an element of information (Poirier et al., 1995).

Following a period of data immersion and inductive analysis, which made it possible to identify new relevant themes, we completed a thorough cross-check of the codes and themes emerged. To ensure reliability and credibility of the results, we created a common codebook to analyse all the data collected. The codebook included a priori categories such as: the experience of care, feelings/emotions, communication among all stakeholders, ethical issues and ethical decision-making, and emerging categories in the data, such as parents' and health professionals' learning, metaphors, and images. We analysed and processed all the narratives with the qualitative analysis software NVivo (version 12 Pro).

\section{FINDINGS}

The narratives of parents, although varying in form, had a depth of content at the starting point and were all structured, without exception, around a set of events such as birth and/or delivery, the first contact with the baby, hospitalization, critical episodes, developmental milestones, discharge, and the child's death (when it occurred). The parents' narratives often resorted to description of places, interactions, conversations/dialogues, and situations, while simultaneously evoking or explaining feelings and emotions. Health professionals wrote mainly about ethical issues and decision making that they face during their work at NICU. In the findings below, participant numbers beginning with " $M$ " or "P" are in reference to parents. Those beginning with "N" or " $\mathrm{D}$ " refer to healthcare professionals. 


\subsection{Parents' perceptions}

The parents' narratives revealed that they value the quality of the NICU for its technological support as well as for the well-trained staff, capable of addressing the needs of their babies and of themselves. They also conveyed the impact of their first contact with their premature babies, which caused surprise, sometimes shock, but also admiration, tenderness, and love. Fathers emphasized the need to control all situations, particularly concerning the mothers' health and life, occasionally also hospitalized in intensive care, as well as the child's health and survival. Some mothers of premature babies defined themselves as premature mothers, meaning that they became mothers before the right time without fully preparing for motherhood, feeling the need to grow up and adapt to a new and challenging life.

Parents' perceptions revealed their main concerns were with their children's fragility and vulnerability, the burden of tragic moments, and their children's resilience or survival. They also expressed feelings of gratitude to health professionals. A special emphasis was placed on the care provided by nurses, specifically on the sensitivity and affection in the touch and care of their children. Participant M13 noted, "My baby was cared by devoted doctors and nurses that, as often as possible, tried to keep the bond between me and my child and informed me about the clinical condition and evolution in a realistic way." M14 expressed that, "(At NICU) all babies were monitored, constantly watched over (supervised) by NICU staff, who were always ready to take care, treat and at same time, cuddle them." Similarly, M18 explained, "My baby was presented to me in a big room with twelve incubators, with professionals that move silently, accurately and safely." M2 wrote, "We have an enormous respect and gratitude to NICU staff, especially for the patience and delicacy towards our little baby... all this care goes beyond their duties." According to $\mathrm{P} 1$, "All professionals are unbeatable in their efforts to keep the life and wellbeing of our babies." Finally, M18 indicated:

We (me and dad) kept firm day after day, under the attentive look of the staff, who provided not only precious technical care but also love, physical, mental, emotional and energetic availability to all babies and parents, as a family. We could see hope and sometimes dismay and discouraged in their eyes. 


\subsection{Parents' feelings and emotions}

Participant M10 wrote in her narrative, "My experience at NICU could be defined as a roller coast of feelings and emotions." The negative emotions expressed by parents in their narratives were anxiety, affliction, anguish, sadness, fear (which is central to many narratives), emptiness, shock, and suffering. These emotions were all related to the fragility and vulnerability of the newborns, emphasized during the hospitalization period. There was also a group of conflicting emotions, such as resignation, anger, envy (specifically related to other parents), and guilt (due to the fact that they account themselves as responsible for their newborns clinical situation). These emotions are shown in Figure 1 below.

Positive emotions were mainly related to the positive clinical evolution of their babies. Some special events or moments evoked by parents were of great joy and satisfaction, namely when they could touch the baby, conduct skin-to-skin contact (Kangaroo care), participate in daily care, breastfeed, and prepare to discharge from the hospital. Parents' expressed in their perceptions of NICU staff behavior and attitudes. For example, M19 wrote, "The nurses, doctors and medical auxiliary staff are amazing people, that everyday work also mitigating our pain and suffering." P5 explained, "The more interesting experience in NICU was caring for the parents' needs and the loving hands taking care of our children. We stayed there for a long time, and all (staff) understood our anguish and took care of our suffering."

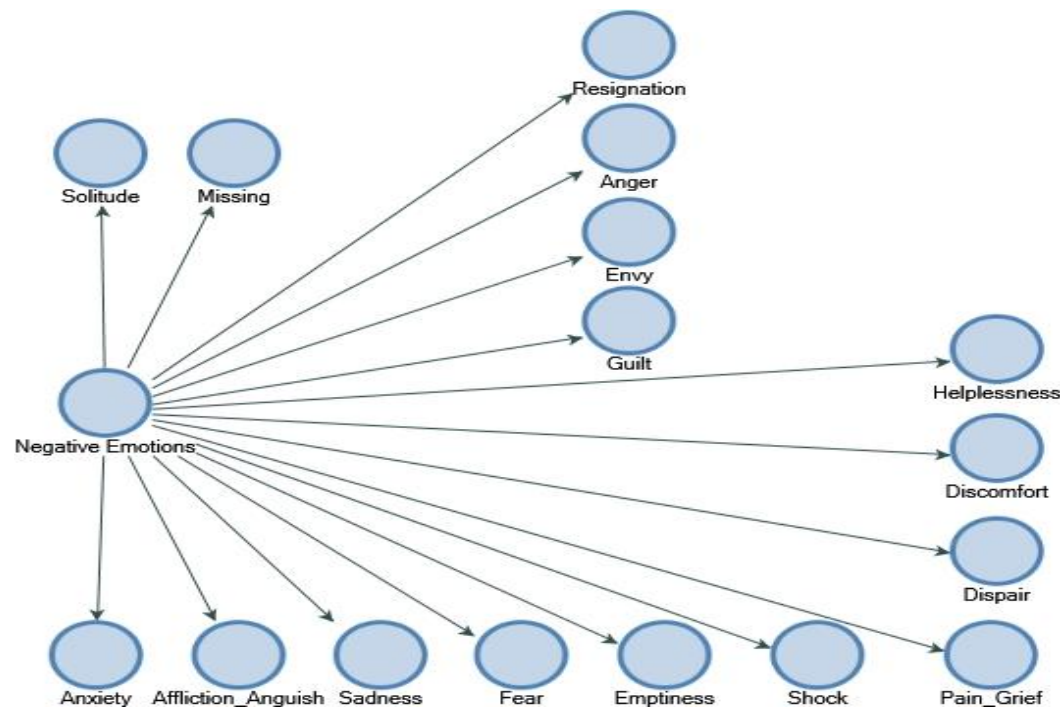

Figure 1. Negative Feelings or Emotions 


\subsection{Healthcare professional's feelings/emotions}

This category of emotions and feelings was much less expressive in the narratives of health professionals. They used a more clinical and technical language, which might have been related to their daily practice and the need for emotional control in intensive care work. Some narratives highlighted satisfaction and joy after successful completion of complex procedures. Feelings of joy and success during successful resuscitation were also frequent, as well as feelings of sadness, failure, and frustration when the resuscitation failed. Some professionals revealed signs of physical and psychological distress related to difficult decision making and the grief process.

\subsection{Parents' learning}

Parents of hospitalized newborns are subject to psychological distress related to their infant's health and survival, risk of disability, family disruption, and physical and emotional features of NICU environment. Most parents' narratives emphasized coping strategies that we grouped into four main areas: (a) the bond with their babies: touching, holding, massaging, Kangaroo care, speaking or singing; (b) personal life, mainly self-caring: prioritizing their personal health, sleeping, doing exercise and eating properly, spending time with family and friends; (c) psychological support: being able to share thoughts, feelings and experiences; and (d) the bond with other NICU parents. As examples, the following extracts reveal the learning process underlining the experience of premature babies' or critically ill infant's parents:

- "To survive, I must learn to live one day at time" (M4).

- "This experience has taught me to love unconditionally" (M9).

- "We have to learn to accept our child with limitation[s] and deficits" (M17).

- "I have learnt to enjoy the few but great moments and to minimize daily problems" (P2).

- "Our loss was very difficult to accept, we had to relearn how to live without our baby" (M2).

\subsection{Health professionals' learning}

Health professionals' learning related to a respect for the newborn physiology, behavior, resilience, and their peculiar way of communicating. There were narratives that highlighted the extraordinary strength of some babies and the relevance of subtle and small, but 
important, signs, such as behavior, movements, grimaces, and other signs of comfort or discomfort. Also relevant was the human and relational growth with parents and the rest of the team as well as dealing with their own feelings about loss and death.

\subsection{Communication among all stakeholders}

Participant M5 wrote:

Although she [the doctor] talked to us calmly, I just retained part of the information, most of words I'm sure I didn't hear. It seems a nightmare. I realized that when we are fragile, words have such an enormous impact. Something that in another situation is vulgar, becomes much too relevant.

This brief report reveals how communication assumed a relevant role in this context and posed important challenges to all involved. The success of the communication process did not depend exclusively on the sender's communication skills, but on the receiver's ability and willingness to listen, a condition that, for various reasons, cannot always be guaranteed. However, the narrators, consciously or unconsciously, identified a set of elements that facilitated and/or inhibited the communication process.

\subsection{Parents' perceptions of communication - facilitators}

The main facilitators of communication that we identified were: the relevance of complete information about NICU rules and clinical issues, clarifications of doubts, parenteral expectations management, active listening, emphatic attitude, emotional and psychological support, and reduction of uncertainties. The narrators emphasized the relevance of the various dimensions of communication such as: time, place, attitude, and mode of communicating.

Also relevant were the voice tone, facial expression, clarity, and terminology used. For example, participant P4 wrote, "For us, the "hidden" help [given] by the team was essential, including the content of the information, the moment and the way they did it." M16 expressed, "We emphasise the management of emotions and expectations, the professional way they shared the information and decision making, the empathy with our feelings (floating and sometimes contradictory), the performance of those professionals that daily work at NICU." M1 explained: 
We all stayed together, me and my husband, the doctor and the nurse. I saw my husband crying for the second time. I remained calm all the time. I was there for my baby, my little girl. We went home after she died, during the night. The shift was over, but no one left.

Finally, M2 noted:

We were very happy in NICU. All the staff, doctors and nurses and other parents became part of our life. For some time, that NICU was our home. We laughed, cried, unburdened, we waited for so many answers... We have an enormous respect and appreciation for all the NICU staff, for their patience and kindness and for all their attention when caring for our baby.

\subsection{Parent's and Healthcare Professionals' Perceptions of Communication - Barriers}

The main inhibitors or obstacles to communication identified by parents and health professionals were related to the transmission of bad news, the unpredictability of outcomes, contradictory information, and a non-empathic way of communication. Some health professionals wrote about the difficulties they felt when they had to give bad news, underlining the need for more training in this area. Illiteracy or cognitive disturbances of some parents were also referred to as obstacles to adequate communication.

The excessive amount of work within the health professions and their impact on the time needed to communicate was also referred to by some parents as a negative element. For example, participant M1 wrote "One day my baby had apnea, the alarms didn't work correctly. She was immediately reanimated by the nurse. The doctor was too harsh during the explanation. I started feeling fear that something wrong could happen." M13 explained:

The day of prenatal diagnosis will stay forever in my mind. I'll never heard so big and so painful swear-word. Hernia what? What's that? How could happen? No! My baby must be perfect, we always did everything to be perfect, but wasn't... Every night I called NICU to take my tranquilizer pill. How's my baby? Most of the time the answer was: stable. Health professionals must excuse me, but I start hating this word. I know that means a lot, but nothing for an anguished and anxious mother.

Similarly, M15 noted:

All the time doctors made a meeting around my baby I went out of NICU, to hear without understanding all the weird words they used, which made me feel bad. I always preferred waiting for them to talk to me in a more understandable way, because what we (parents) need is simplicity, the situation is complicated enough. 
Participant M10 wrote, "Sometimes we could realize that the information given by different doctors (of different specialities) was contradictory and this made us feel anxious and insecure."

The Parent's Room is an area near the NICU, where parents can take a break, rest, read, watch TV, chat with other parents, or write. This place was generally considered by parents as a good one. However, some parents saw it as a source of negative feelings and conflicts, because this is where parents usually compared their babies, who were at different stages of hospitalization, leading to uncomfortable conversations and feelings of sadness, pessimism, envy, and anguish.

\subsection{Parents' and healthcare professionals' perceptions of ethical issues and decision-making}

The ethical issues included in the narratives were mainly in the area of decision-making especially related to withholding or withdrawing treatments. Decision-making was referred in almost half of the narratives. Participant N2 wrote, "The reasonableness of proceeding with successive reanimations started to be questioned by the team." N13 explained, "Several times we questioned ourselves about the limits, if they were or not exceeded." N14 expressed, "We [the NICU team] share the anguishes and doubts about how far to go and insist." Finally, N21 noted, "The impact of our intervention on family and society is powerful and sometimes overwhelming."

Doctors must help parents understand their children's clinical situation and prognosis but they should also clarify the meaning of the choices they face in light of that clinical situation. NICU staff team must first help parents articulate their own hopes, fears, and values and integrate all these in the deliberative procedure and final decision. Participant N21 explained, "There is a hard fight for survival; we work between some parent's requests (don't let him go, he will make it, he's strong, he's my son...) and the limits of our intervention (appropriate or excessive, obstinate?)." N25 wrote, "Several times I thought: is it worth all the efforts? Are we dealing with therapeutic enhancement? Would palliative care be better choice? Should we decide for the natural course of the disease?"

In neonatology, these tasks are particularly tricky because parents in the NICU are in the grip of very strong emotions, as discussed above. This emotional ground makes it difficult for most parents to understand and interpret information about the complex probabilities of 
various outcomes. These facts are the main topics mentioned in health professional's narratives, stressing the difficulties in communicating with some parents, in making difficult decisions, while underlining the impact that this hard context has on their own life and health. Participant N7 wrote:

The decision was very hard to all team [members], unimaginable to parents. Their wish to understand the etiology of the tragic event was relevant in final decision to maintain vital support until the laboratory test could be made to confirm the diagnosis.

E4 indicated, "We questioned about the value of life and death, the difference between surviving with severe sequels or neonatal death; about proceeding treatments or setting up limits, taking into account the quality of life."

In most cases, parents stress the dilemma between saving the life of their baby with longterm severe sequelae or, otherwise accepting neonatal death. Some mentioned palliative care, although omitting the term. For instance, participant M1 wrote:

One Friday afternoon, doctors came and talked to me. I heard and I called my husband. I could never express what I felt at that moment. Laura had multiple cerebral abscesses. Me and my husband had no doubts that it would be better if she died... well, I had some... for a while, I thought maybe it could have been a misdiagnosis...I had a shred of hope.

M9 explained, "My little girl is under tracheostomy, home ventilated and with a percutaneous gastrostomy, but always very attentive, intelligent and trying to communicate through PC EYE GO."

\subsection{Metaphors and images}

Participant P5 wrote, "Our routine has been modified like a Tsunami, but with enormous love, literally incubated, all of our difficulties became soften[ed], sprawled out and evaporated." The metaphors and representations, which were used to facilitate the expression and reveal the subjective view of the world, enable alternative ways to understand the environment that surrounds us and to intervene in it. We have therefore decided to analyse the set of metaphors that emerged in the narratives of parents and professionals.

Metaphor, as a rhetorical figure, was recurrent in parents' narratives, helping them to talk about difficult moments and to face negative emotions and feelings that would be otherwise impossible to describe. Healthcare professionals did not use images or metaphors in such an 
expressive way, maybe due to the common use of technical language and the prevalence of rationality at the expense of emotion in their discourse. We found metaphors and images in 24 narratives, mainly in parents' narratives. "Fairy-tale" metaphors were very often used by parents to convey the way they saw their babies and to express admiration, tenderness, and love. These included the use of words such as pearl, princess, prince, or princess dancer. "War" metaphors, were used when parents described their newborns' resilience, in spite of their great fragility and vulnerability, with words like hero, fighter, fight, warrior, victory, brave, lost the battle, win the war

The images were mainly used to explain feelings and strong emotions related to life events, such as significant and/or tragic moments. For example, M4 wrote "You went through the raindrops without ever getting wet." M15 explained, "The clinical condition rapidly worsened. It was a cold shower." Participant M17 expressed, "A bright and valuable stone on millionaire's shoes. I was a trapeze artist, a colourful and magical whirlwind." M9 indicated, "At beginning the days are hours, the hours are minutes and the minutes are seconds. Everything changes in a stunning speed, causing a vortex of emotions that leads us between sanity and madness." M8 noted, "At that moment the ground began to slip away, and I was falling into a black hole." As another example, participant M20 penned, "My experience in NICU was hell. The pain, suffering and fear for our child's life and outcome uncertainty is so tearing that no happy end could fade. It is always, always in my memory and engraved on my heart." P10 wrote, "I could finally rest, but then suddenly a train of problems and scenarios appeared that ran over us daily." Finally, M12 recorded, "When my [was] baby born so prematurely and was admitted in NICU, I froze my heart and I promised that it would only restart beating when I would be able to take my baby home."

Parents also used images to express gratitude and respect to the health professionals. M17 wrote, "Fairy ladies with cotton fingers passed around." P1 penned, "Our babies were strong and fighters and thanks to yellow angels they won. We will never forget those angels, that work hard to save our kids." M10 noted, "The staff's professionalism and care, helped us not to 'throw the towel down,' but gave us the strength "keep on the road."

The health professionals' metaphors and images were less expressive, although war metaphors, similar to those used by parents, were found in some narratives. Metaphoric language was more prevalent among female younger doctors. For instance, participant N10 noted, "Some histories get tattooed on our soul." N15 wrote, "She was our little girl rice 
grain." N21 penned, "We control medical devices because they are like nomads." N6 recorded, "Some babies are low in their gestational age but giant in their desire to live." Finally, N1 wrote, "Most preterm babies are XXS size but XXL in strength and fortitude." These are preliminary findings.

\section{DISCUSSION}

The present study, the first to be carried out in a Portuguese NICU, emphasizes the relevance of narratives in the alignment of parents' and healthcare professionals' perspectives, so that the therapeutic relationships can be built in the best interest of the newborns. It is important to underline that, in spite of the PI having already had a relationship with the parents and a previous knowledge about the clinical course of their babies, which might explain the adherence to participation, this fact did not prevent the narrators from exposing some negative aspects regarding communication with the staff and organizational problems.

Although most health professionals that participated in this study have more than ten years of work experience at the NICU, their narratives express doubts, uncertainties, and ethical issues, mainly related to withdrawing and withholding treatments. Also relevant was the evidence of self-care needs referred to by some professionals as well as the need to promote brainstorming meetings after difficult decisions. Psychological support is available for NICU staff; however, based on health professionals' narratives, this support should be carried out on a more regular basis. In more complex cases, there should also be a more graduate neonatologist supporting the multidisciplinary team, gathering all the information and sharing it with parents.

The American Academy of Pediatrics (AAP) prioritizes shared decision-making between parents and physicians. Some studies confirm that families wish to participate, to some degree, in decision-making (Clarke-Pounder et al., 2015; Levetown, 2008). A truly shared decision making is difficult under any circumstance (Weiss et al., 2016). But in neonatology, the uncertainty of the prognosis, the urgency of time, and sometimes the fact that there is not one single patient but two (the critically ill infant and the mother), make things worse (Lantos, 2018). These aspects were very clearly stated by parents and health professionals in their narratives. Improving knowledge in bioethics and in Narrative Medicine could provide NICU staff with better communication and shared decision-making tools (Fioretti et al., 2016). 
Based on these preliminary results, it is possible to point out an important guideline: between war and fairy-tale metaphors, there is common ground to promote reflective rounds with health professionals and parents, which could balance the fairy-tale elements of the care, together with realistic facts about the newborn health condition. Metaphor, as a rhetorical figure, is recurrent in parents' narratives, as it helps them to express difficult moments, as well as emotions and feelings that would be otherwise impossible to describe. Health professionals do not use images or metaphors in such an expressive way, maybe due to the facility and training in technical language or due to the fact that rationality tended to be more prevalent than emotional discourse. Metaphors and the most common terms and categories used in the narratives of the different group of participants disclosed how, where, and why one should intervene to improve communication and shared decision making so that the care provided can be more effective and person-centered.

The strengths of our study are the virtues and advantages of a qualitative study to collect the emotions, feelings, opinions, and perceptions of parents and health professionals. We also stress the potentiality of the narratives used as a completely open, unstructured, and nondirective instrument of data collection. The institutional nature of our research could be considered a limitation, but the following arguments contradict this position:

1. Qualitative research does not visa the generalization of the results.

2. The research has been carried out based on the knowledge of neonatal clinical histories, which contributed to a deep and accurate reflexive analysis, interpretation, and understanding of the parent's narratives.

3. Other NICU/institutions can replicate the study.

4. The main aspects of this study will be discussed with peers.

\section{CONCLUSION}

In conclusion, we believe that improving knowledge in bioethical principles and acquiring skills in Narrative Medicine could help NICU staff to better communicate with parents, to be more able to deliberate, and to share decision making within the neonatal setting. The analysis of narratives within a Narrative Medicine framework allowed us to identify the terms, images, and metaphors in the discourse of parents and health professionals in order to provide guidelines for their alignment as well as for the necessary changes in daily practice. The results allow us to recognize the relevance of promoting instruments, skills and strategies to provide parents with more accurate information about hospitalization, namely 
regarding coping strategies. In the present study the authors emphasize the role of the intersubjective bridge between bioethics and Narrative Medicine.

Conflicts of interest. The authors declare no conflicts of interest.

Acknowledgments. The authors thank all participants (parents and healthcare professionals), for their collaboration in writing the narratives.

\section{REFERENCES}

Arzani, A., Valizadeh, L., Zamanzadeh, V., \& Mohammadi, E. (2015). Mothers' strategies in handling the prematurely born infant: a qualitative study. Journal of Caring Sciences, 4(1), 13-24. https://doi.org/10.5681/jcs.2015.002

Beals, D. (2016). Neonatal bioethics. In T. L. Gomella, M. D. Cunningham, \& F. G. Eyal (Eds.), Neonatology: Management, procedures, on-call problems, diseases, and drugs (pp. 221-226). McGrawHill.

Cassel, E. (2011). The nature of suffering and the goal of the medicine. Oxford Scholarship Online. https://doi.org/10.1093/acprof:oso/9780195156164.001.0001

Charon, R. (2001). Narrative medicine: Form, function, and ethics. Annals of Internal Medicine, 134(1), 83-87. https://doi.org/10.7326/0003-4819-134-1-200101020-00024

Clarke-Pounder, J. P., Boss, R. D., Roter, D. L., Hutton, N., Larson, S., \& Donohue, P. K. (2015) Communication intervention in the neonatal intensive care unit: Can It backfire? Journal of Palliative Medicine, 18(2), 157-161. https://doi.org/10.1089/jpm.2014.0037

Fioretti C., Mazzocco, K., Riva, S., Oliveri, S., Masiero, M., \& Pravettoni, G. (2016). Research studies on patients' illness experience using the Narrative Medicine approach: a systematic review. BMJ Open 6(7), 1-9. http://doi:10.1136/bmjopen-2016-011220

Gracia, D. (2003). Ethical case deliberation and decision making. Medicine, Health Care, and Philosophy, 6(3), 227-233. https://doi.org/10.1023/A:1025969701538

Hawley, S. T., \& Morris, A. M. (2017). Cultural challenges to engaging patients in shared decision making. Patient Education and Counseling, 100(1), 18-24. https://doi.org/10.1016/j.pec.2016.07.008

Hurwitz, B., \& Spinozzi, P. (2011). Narrative (in) medicine. In: Spinozzi, P., \& Hurwitz, B. (Eds.), Discourses and narrations in the biosciences (pp. 73-87). Vandenhoeck \& Ruprecht Unipress.

Lakoff, G., \& Johnson, M. (2003). Metaphors we live by. The University of Chicago Press.

Lantos, J. D. (2018). Ethical problems in decision making in the neonatal ICU. New England Journal of Medicine, 379(19), 1851-1860. https://doi.org/10.1056/NEJMra1801063

Lefkowitz, D. S., Baxt, C., \& Evans, J. R. (2010). Prevalence and correlates of posttraumatic stress and postpartum depression in parents of infants in the neonatal intensive care unit (NICU). Journal of Clinical Psychology in Medical Settings, 17(3), 230-237. 
https://doi.org/10.1007/s10880-010-9202-7

Levetown, M. (2008). Communicating with children and families: From everyday interactions to skill in conveying distressing information. Pediatrics, 121(5), 1441-1460. https://doi.org/10.1542/peds.2008-0565

Lieblich, A., Tuval-Mashiach, R. \& Zilber, T. (1998). Narrative Research: Reading, Analysis, and Interpretation. SAGE. http://doi.org/10.4135/9781412985253

Murphy, J. W., Choi, J. M., \& Cadeiras, M. (2017). The role of clinical records in narrative medicine: A discourse of message. The Permanente Journal, 20(2), 103-108. https://doi.org/10.7812/TPP/15-101

Poirier, S. (1999). Voice: Structure, politics, and values in the medical narrative. HEC Forum, 11(1), 27-37. http://doi.org/10.1023/a:1008852301505

Poirier, J., Clapier-Valladon, S., \& Raybaut, P. (1995). Histories of life: theory and practice. Celta Ed.

Purdy, I. B., \& Wadhwani, R. T. (2006). Embracing bioethics in neonatal intensive care, part II: Case histories in neonatal ethics. Neonatal Network, 25(1), 43-53. https://doi.org/10.1891/07300832.25.1.43

Squire, C., Andrews, M., Davis, M., Esin, C., Harrison, B., Hyden, L., \& Hyden, M. (2014). What is narrative research? Bloomsburry Academic Ed.

Tekiner, H. (2017). Ethical considerations related to narrative medicine. In O. Sayligil (Ed.), Patient centered medicine (pp. 161-175). Intech Open. https://doi.org/10.5772/66167

Weiss, E. M., Barg, F. K., Cook, N., Black, E., \& Joffe, S. (2016). Parental decision-making preferences in neonatal intensive care. Journal of Pediatrics, 179, 36-41. https://doi.org/10.1016/j.jpeds.2016.08.030

Wigert, H., Blom, M. D., \& Bry, K. (2014). Parents' experiences of communication with neonatal intensive-care unit staff: An interview study. BMC Pediatrics, 14(1), 1-8. https://doi.org/10.1186/s12887-014-0304-5

Zonza, M. (2012). Narrative based medicine and neonatology: An interpretative approach. Journal of Pediatric and Neonatal Individualized Medicine, 1(1), 49-52. https://doi.org/10.7363/010114 